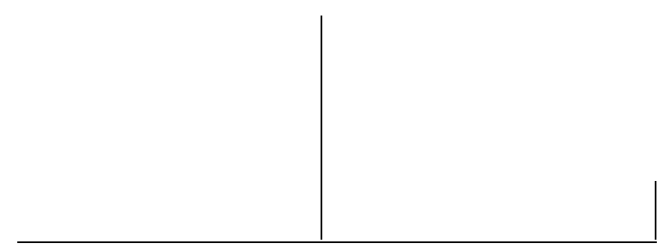

Rev. Latinoam. Psicopat. Fund., VIII, 4, 617-628

\title{
A função reguladora do transe e possessão ritual nos cultos espiritistas brasileiros
}

\author{
Fernando Portela Câmara
}

\begin{abstract}
O autor considera neste trabalho as práticas de cura baseadas em cultos animistas bastante difundidos no Brasil. Esses cultos têm como princípio a conversão de seus líderes espirituais após serem curados por suposta intervenção de espíritos tutelares do culto. Estes líderes são, eles mesmos, exemplos do poder dos espíritos em sua comunidade e mediadores entre os membros e os espíritos. O autor considera que estes cultos de cura e conversão têm como base o fenômeno do transe e possessão, o qual, sendo controlado, tem propriedades dessensibilizantes, devolve o autocontrole e libera as forças criativas do indivíduo. Amplia ainda este conceito, considerando tal prática como a base de uma transeterapia inserida na cultura popular.
\end{abstract}

Palavras-chave: Transe e possessão, cultura popular, psicoterapia 


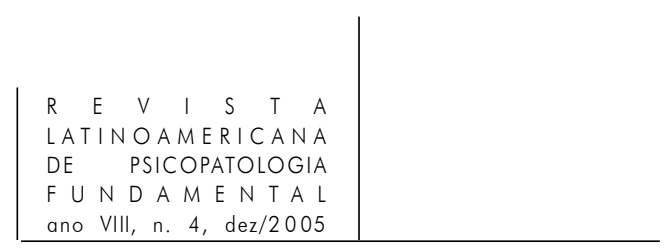

As culturas ditas "primitivas” têm seus próprios métodos para abordar e lidar com os transtornos mentais e do comportamento. Estes métodos permanecem na cultura popular, formando o núcleo das chamadas seitas animistas ou "espiritistas". Nestas seitas ou "centros", tal cultura assume um valor psicossocial inquestionável, não apenas nas chamadas "camadas populares", como também nas camadas economicamente superiores. Organizadas no seio do povo, estas seitas desempenham uma função assistencial imensa, preenchendo a ausência do Estado na saúde da população, especialmente na saúde mental. A expressão seita espiritista será usada neste trabalho em lugar de seita animista, pois, no Brasil, o primeiro termo é melhor conhecido e aceito; enquanto o segundo, de origem européia, é visto por alguns como racista. Também não discutirei aqui interpretações psiquiátricas ou psicodinâmicas do espiritualismo, respeitando a crença dos leitores, sendo meu objetivo aqui apenas discutir o possível valor terapêutico destas práticas, que encontra em nosso país dezenas de milhões de seguidores.

O saber psiquiátrico, como todo o saber médico em geral, é hoje essencialmente um saber acadêmico de origem européia, com paradigmas espelhados no inevitável racismo científico eurocêntrico e mentalidade colonialista. Esta atitude influi de modo sutil, porém intenso, nos modelos médicos assistenciais e nos modelos aplicados à saúde mental (Chakraborty, 1991; Sashidharan, 1986). A pressão econômica que a aculturação deste saber exerce sobre os países do Terceiro Mundo impacta o modelo de saúde mental adotado, encarecendo-o consideravelmente na proporção em que ele se afasta radicalmente da cultura popular (Loyola, 1984). O resultado é uma oposição de dois paradigmas: o modelo psi de um saber dominante (eurocêntrico) cultural, social e economicamente imposto, e o modelo psi de um saber que ainda resiste em nossa cultura popular, e se refugia no seio das comunidades em organizações conhecidas como "centros" e "terreiros". 
Costumo dividir as seitas espiritistas brasileiras em 1. espiritismo Kardecista, ou espiritismo "branco", de "mesa" ou "científico", de origem européia porém aclimatado à cultura brasileira, onde sincretizou-se absorvendo influências católicas e afro-brasileiras (Procópio, 1961); e 2. as seitas de origem africana, como a Umbanda (a mais sincrética, ocorrendo em todo o país), o Candomblé (a mais tradicional), a Quimbanda (Centro e Sul), o Xangô e o Catimbó (Nordeste), o Batuque (Sul), e outras mais regionais, bem como as de origem ameríndia, como a Pagelança e o Paricá (Cascudo, 1980).

O elemento central a todas estas seitas é o fenômeno de transe e possessão, o instrumento comum que permite aos médiuns intermediarem os "espíritos" de pessoas já mortas (Kardecismo), ou com espíritos tutelares da natureza (os Orixás), aos membros e simpatizantes das seitas. É interessante assinalar que a Igreja Católica, religião oficial do Brasil, não reprime a participação de seus filiados nestas seitas, ao contrário das religiões protestantes e pentecostalistas, que competem economicamente com as citadas seitas, embora sejam parte da mesma cultura do transe. Na verdade, a Igreja católica não impede a participação de seus fiéis nestes cultos, desde que isto se dê em participações individuais e não em celebrações que envolvam a sociedade civil (Oliveira, 1977).

Os transes rituais comumente vistos nos centros e terreiros produzem uma intensa descarga de energias afetivas patogenicamente represadas, gerando autoregulação organísmica e bem-estar biopsicossocial. São crises de natureza abreativa, não verbais, de inquestionável valor terapêutico. Como salientou Louis Mars (1955), é um mecanismo psicobiológico de defesa e não um estado mental patológico, mas um mecanismo destinado a integrar funcionalmente o sujeito dentro de um complexo cultural. Ele classifica esta manifestação cultural terapêutica como um "psicodrama étnico".

\section{Transe e possessão}

Transe é um estado modificado de consciência em que esta se interioriza e manifesta vivências habitualmente reprimidas na vigília. Estas vivências são atuadas freqüentemente - se o millieu é permissivo - como uma dramatis persona. Temos recordações, fantasias, dramas, e também personagens defuntos ou espíritos tutelares -, "entidades” que exercem uma função reguladora no grupo social que se reúne em torno desta crença. As características psíquicas deste estado são típicas: rapport, sugestionabilidade aumentada, estereotipias, literalismo, exibicionismo ou teatralismo etc. Não há relação entre transe e transtorno de personalidade, especialmente com o transtorno de personalidade 


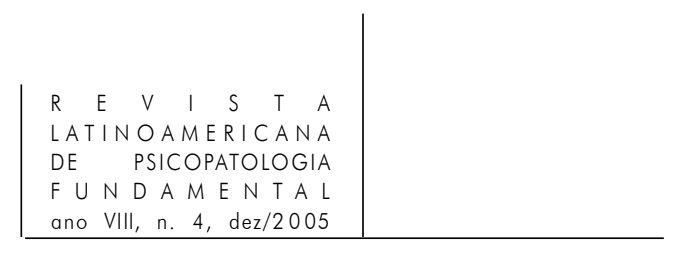

histriônica (Spiegel, 1972, 1974; Spiegel et al., 1982). Também temos fenômenos somáticos associados, tais como analgesias, automatismos etc., que parecem indicar a participação de estruturas subcorticais. O transe pode ser induzido artificialmente ou espontaneamente, e é de natureza reversível, havendo pessoas com maior facilidade para este estado, o qual também pode ser facilitado e controlado pelo treinamento (Spiegel, 1974; Câmara, 1996). Pode se manifestar meramente como inibição de consciência com vivências de bem-estar ou de conteúdos intrapsíquicos, ou pode vir acompanhado de manifestação de personalidades estereotipadas (ou "estados segundo", na terminologia de Azam, 1887). Neste último caso temos o estado caracterizado como "transe e possessão", a categoria de transe sobre a qual se organizam as seitas espiritistas em qualquer parte do mundo.

Nos grupos onde este fenômeno é culturalmente aceito, transe e possessão podem manifestar-se durante um choque emocional, conflitos conjugais ou familiares, exposição à miséria e violência, como uma forma de lidar com tais situações. Neste caso, o transe exerce um papel regulador, permitindo a descarga das energias emocionais patogênicas socialmente inadequadas. Tais manifestações são culturalmente aceitáveis somente se limitadas a estes contextos, e, fora deles, são energicamente reprimidas pelo grupo, mostrando como a comunidade dá importância ao seu papel terapêutico ou regulador. Nas festas tradicionais como o Carnaval, as celebrações da Sexta-feira da Paixão etc., e nos espetáculos coletivos, o transe torna-se um regulador psicobiossocial. Nas seitas espiritistas, este processo é desempenhado pelos ritos conduzidos pelos médiuns. Estes são indivíduos treinados (ou “desenvolvidos”) pela seita após terem seus sintomas psicossociais controlados pela prática disciplinada e regular do transe. De fato, quando médiuns são privados de seus transes regulares, por uma censura imposta pelo meio ou por estarem fora do seu millieu, eles freqüentemente desenvolvem sintomas que apresentavam antes de terem sido treinados. São estas as "doenças espirituais" habitualmente tratadas nos centros e terreiros por meio da dessensibilização pela prática regular e supervisionada do transe, até o indivíduo aprender a controlá-lo. Tais doentes nervosos são tidos como "médiuns naturais" que, por não terem desenvolvido o seu "dom", sofrem por reprimirem a manifestação de "espíritos" que canalizam até serem submetidos a sessões de "desenvolvimento da mediunidade", que é o aprendizado do controle do transe em sessões regulares de efeito dessensibilizador e educativo.

A chamada "Síndrome da Personalidade Múltipla" (atualmente Transtorno Dissociativo de Identidade) nada mais é que um desvio cultural desta função, percebida pela sociedade como um "transtorno", freqüentemente de caráter iatrogênico. Sendo tal condição considerada inadequadamente um transtorno psiquiátrico, não será objeto deste artigo. De fato, o papel de regulação 


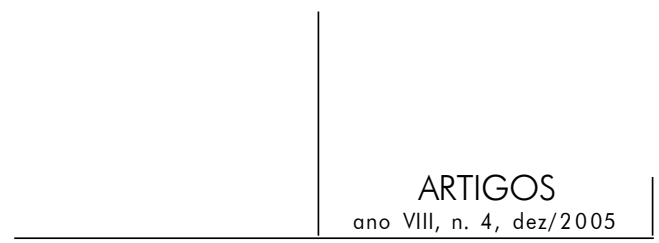

biopsicossocial do transe e possessão em nossa cultura faz com que síndromes tais como personalidade múltipla e correlatos existam em outras culturas como transtornos, mas não entre nós, ou enquanto não nos aculturarmos nessa direção. Nos EUA, o alheamento do aspecto sociocultural desta forma de manifestação, impedindo o seu benefício abreativo, acabou por incentivar a síndrome da personalidade múltipla, porquanto tais indivíduos são impedidos pela censura social de dar curso livre à sua ab-reação. Curiosamente, nesse país, onde os cultos pentecostalistas proliferam nas regiões rurais, o problema da personalidade múltipla passa a ser regulado neste millieu, por meio dos exorcismos e transes cinéticos (danças e estereotipias motoras) conduzidos por aqueles cultos. A desconexão da sociedade americana urbana com o seu passado e tradições rurais onde a cultura do transe (Quackers, Pentecostalistas etc.) é preservada nos cultos Gospel e revivalistas, foi talvez a principal responsável pelas epidemias de personalidades múltiplas vividas naquela sociedade.

\section{A formação dos médiuns. Transeterapia}

O médium é a figura central nas seitas espiritistas, exercendo um poder espiritual na comunidade ao seu redor, ajudando as pessoas com seus conselhos e magias, e promovendo a solidariedade pelas práticas de caridade. Os médiuns são geralmente pessoas humildes que foram curadas de algum mal nervoso (simbolizado como uma possessão descontrolada) por outros médiuns, e por meio desta cura são convertidos ao credo da seita espiritista que os acolheu. Isto é um processo de iniciação, e não é diferente da iniciação dos antigos mistérios, onde o indivíduo é submetido a uma terapia espiritista concluindo sua cura com um processo de conversão religiosa. Talvez isto não seja muito diferente do que ocorre em uma análise didática.

Os indivíduos procuram uma seita por necessidade ou por pressão de sua própria cultura. Muitos são padecentes nervosos que encontraram num centro de sua comunidade alívio e cura para os seus males, após bater de porta em porta nos labirintos da medicina oficial, um modelo importado tradicionalmente, desconectado da cultura e do imaginário popular (Loyola, 1984). A formação de um médium começa pela seleção dos padecentes nervosos identificados como “médiuns não desenvolvidos”. Os que não preenchem este diagnóstico espiritual são enviados aos médicos e psicólogos que, via de regra, trabalham para o centro. Um médium reconhece a outro médium, e o distúrbio do padecente é tido como uma resistência à livre expressão da mediunidade, portanto, o tratamento será o “desenvolvimento da mediunidade” (ou, nas seitas afro-brasileiras, "vestir o 


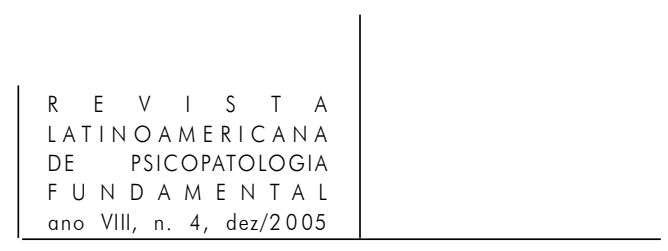

santo", "fazer a cabeça” etc.), que consiste em fazer o padecente manifestar seu transe em dias e horários fixos: as "sessões de desenvolvimento". Este processo de sessões repetidas e disciplinadas é o único meio para levar o indivíduo a aprender a controlar seus transes, cujo desconhecimento e sintomas levam ao medo, ansiedade e somatizações variadas, de natureza quase sempre dissociativas, infelizmente pouco percebidas pela maioria dos nossos psiquiatras, distanciada do popular e do folclórico, e cuja práxis não reconhece os elementos terapêuticos desta cultura.

O processo misto de terapia e iniciação, conhecido como "desenvolvimento da mediunidade", consiste em disciplinar os transes descontrolados do indivíduo, promovendo repetidas abreações vegetativo-motoras, não-verbais, até a sua completa dessensibilização. Daí emerge uma personalidade equilibrada, tranqüila, livre de seus padeceres neuróticos, e que mantém sua homeostase nervosa através dos transes regulares no centro ou terreiro, geralmente associados a trabalhos de cura e assistência à comunidade que busca auxílio espiritual e psicológico em tais lugares. O médium agora ganha importância em seu meio, aprende a entrar e sair de um transe, controlando agora o que antes se manifestava de forma desordenada e descontrolada, causando-lhe medo, dissociação, mal-estar e sofrimento. O médium que se especializa em transe e possessão passará a ser veículo (ou "aparelho", ou "cavalo") de uma entidade tutelar da seita, que pode ser o espírito de um morto ilustre ou um orixá, que através dele "disponibiliza conhecimentos do mundo espiritual” para aconselhar, prever, diagnosticar, tratar e tudo mais.

As seitas espiritistas desempenham funções sociais como parte da sua razão de existir, sendo suas finalidades primárias a promoção da cura e da caridade. Os médiuns canalizam a cura e as mensagens das entidades para a comunidade, desempenhando o papel do terapeuta no sentido em que esta palavra era usada na Grécia e Roma antigas. É uma tradição que se continua ininterruptamente desde a alta antiguidade até os dias atuais, não sendo muito diferente de outrora nos templos de Asclépio, em Epidauro, sul de Corinto, no século V a.C., que daí se espalharam para toda a Grécia (séc. IV a.C.), Roma (séc. III a.C., com o nome romanizado de Esculápio), Egito (com o nome de Imhotep), Fenícia (com o nome de Esmoun), Cartago etc. Estes médiuns de cura logram muitas vezes mais êxitos com os seus dogmatismos e tabus do que os psicoterapeutas oficiais, reticentes em suas afirmações e atitudes e, particularmente, sem os proclamados "poderes espirituais”.

Nestas seitas também se desenrola paralelamente uma importante atividade formada pelas confissões, obrigações com as entidades, os descarregos, os despachos, as caridades e demais tarefas que promovem também a descarga das energias nervosas tensionais reduzindo o caudal de ansiedade e ainda favorecendo os insights. Os ritos, cultos e obrigações têm a função de restabelecer a 


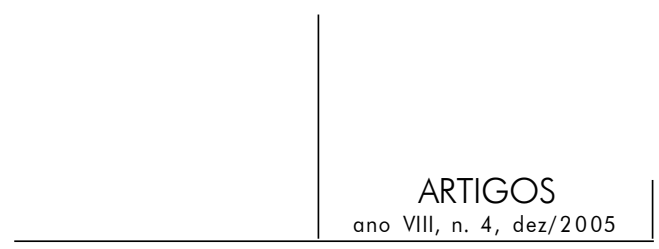

tranqüilidade e o equilíbrio do indivíduo, restituindo sua funcionalidade dentro do seu grupo social e sua família; portanto, cooperam para a homeostase biopsicossocial. É também importante notar que ideologia de não violência e ajuda ao próximo são dogmáticos nestas seitas.

O processo de “desenvolvimento da mediunidade”, portanto, é uma autêntica transeterapia, ou seja, a repetição assistida e controlada do transe, objetivando obter uma dessensibilização progressiva através da ab-reação não verbal, psicomotora e vegetativa, promovendo a cura de distúrbios que em sua natureza são dinamicamente psicogênicos. Os transes são inicialmente agitados e violentos, com intensa descarga vegetativa, depois vão se acalmando com a repetição das sessões, superficializando-se à medida que a dessensibilização progride, até o padecente não mais sentir necessidade deles, ocasião em que o transtorno desaparece. Quando o médium está desenvolvido, seus transes passam a ser ritualísticos, com função psicodramática, servindo à ab-reação do grupo ou então, como mais comumente ocorre, o médium abreage pelo grupo. Lévi-Strauss (1949) tinha observado este mecanismo em culturas indígenas e notou que seu valor terapêutico é da mesma ordem que a ab-reação do paciente. Note-se que a ab-reação, seja por qual via for, embora proscrita da psicanálise, tem seu valor de cura quando o contexto cultural em que se manifesta é permissivo e incentivador. Os transes e possessões rituais têm, portanto, o valor de eficácia simbólica.

\section{Transe e adoecer}

O transe é uma capacidade natural do indivíduo normal que em certas pessoas apresenta-se de forma exagerada e descontrolada (Câmara, 1998, 2001). Estas pessoas são freqüentemente classificadas como portadoras de transtornos dissociativos e seus correlatos, as fobias, o transtorno de despersonalizaçãodesrealização, o transtorno de estresse pós-traumático, o bouffée delirante, e outras condições outrora classificadas como histerismo (Câmara, 1998). No contexto popular, essas pessoas são conhecidas como "médiuns não desenvolvidos", "sensitivos" etc.

A psiquiatria oficial não reconhece os sinais e sintomas do transe. O choque de linguagens entre as culturas da psiquiatria científica e do padecente proporciona um conflito entre ciência e mito, resultando freqüentemente na resistência deste último, que acabará indo a alguma dessas seitas, por pressão de sua cultura. Como já dissemos, manifestações espontâneas de transe são uma tentativa de auto-regulação psíquica, tentativa esta que, muitas vezes, não alcança 


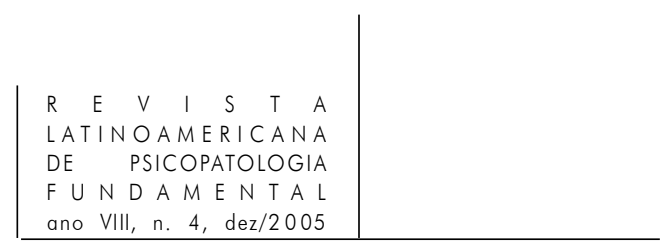

o seu fim, senão um alívio temporário, inadaptado. Se agora este transe é conduzido controladamente na direção da dessensibilização, o indivíduo terá chance de alcançar alívio e adquirir controle sobre seu estado nervoso, promovendo-se a descarga controlada da estase límbico-hipotalâmica, talvez mantida por mecanismos repressores originados no córtex pré-frontal (Câmara, 1997). Este é o princípio da transeterapia, e é isto que também acontece nas sessões de "desenvolvimento da mediunidade" dos centros espíritas brasileiros e nas seitas afro-brasileiras. Eles alcançam um benefício terapêutico real não apenas no âmbito da individualidade, mas também no social, pois estes ritos são integradores e promovem a homeostase biopsicossocial.

O modelo assistencial da saúde mental é extremamente caro e muito se beneficiaria se os órgãos oficiais interagissem com estas seitas que, via de regra, são mantidas pelas próprias comunidades e desempenham um importante papel social. Lideres espirituais destas seitas poderiam ser treinados nos rudimentos da psicoterapia para aperfeiçoarem o seu trabalho e ampliar o alcance assistencial de seus grupos. O papel regular biopsicossocial que elas desempenham é extremamente significativo, mormente nas camadas sociais menos favorecidas, que tendem a crescer mais ainda dentro do atual modelo econômico brasileiro.

\section{Inserção do transe e possessão dentro da psiquiatria cultural brasileira}

A função terapêutica do transe e possessão ritual em nossa cultura foi pela primeira vez reconhecida pelo psiquiatra carioca Jacques Mongruel (1947), numa nota apresentada ao I Congresso Interamericano de Medicina, ocorrido em 1946 na cidade do Rio de Janeiro, em que estabeleceu as bases para um fenômeno cultural que denominou de "Transe Psicautônomo", ou seja, uma manifestação psíquica espontânea de natureza autônoma.

Mongruel estudou particularmente o espiritismo Kardecista, culto extremamente disseminado em nosso país e parte integrante da cultura brasileira. Como não tinha crença espírita, ele adotou uma postura de "investigação psicológica desses comportamentos e não de explicação doutrinária igualmente respeitável” (Mongruel, 1947), e chamou a atenção da comunidade médica brasileira para as "escolas de médiuns", uma característica deste culto. Nelas, como já dissemos, os médiuns, "em sua maioria sofredores nervosos encaminhados ao centro seja por opção pessoal, seja por fatores sociais e econômicos" (ibid.), são submetidos a sessões de "desenvolvimento da mediunidade”. Levam-se semanas ou meses até que estes indivíduos adquirem 


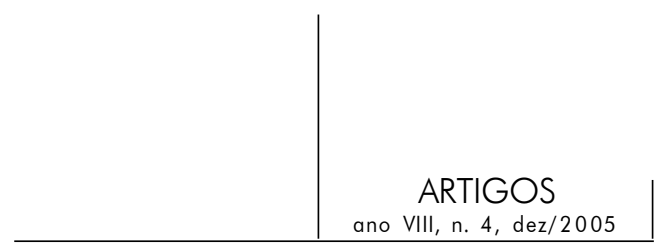

domínio sobre os seus transes, e aqueles que aprendem a recuperar os emocionalmente desajustados são selecionados para trabalharem como médiuns no centro.

Mongruel observou um fenômeno que podemos considerar como essência da transeterapia. Ele concentrou-se na observação de que o transe controlado e repetido liberava um potencial extraordinário de criatividade nos “médiuns desenvolvidos”. De fato, esta é a razão da palavra “desenvolvimento” nestes ritos, e talvez a liberação deste potencial seja o objetivo último desta terapia. Quando o indivíduo adquire controle sobre o seu transe no ambiente destas seitas, muitas vezes passa a falar com lucidez e equilíbrio, aconselhando, julgando com ponderação etc., o que Mongruel chamou transe de "personificação verbal” (ibid.) o que hoje denominamos de "transe e possessão”. São os “espíritos de mortos ilustres” que vêm às sessões comunicar-se com os crentes ansiosos de conselhos e ensinamentos. Também temos os passes e "fluidificação" da água (resquícios do magnetismo animal de Mesmer assimilado à cultura popular desde o final do século XVIII), assim como as operações “espirituais”.

Outra manifestação igualmente importante para a legião de crentes e seguidores destas seitas é a já mencionada “psicografia”, supostas mensagens escritas dos mortos às suas famílias, por intermédio dos médiuns, como também obras de escritores famosos também mortos, peças teatrais, poesias, doutrinas (naturalmente espiritualistas), poemas e canções. Este movimento teve no médium Chico Xavier seu maior expoente, venerado como santo por muitos crentes. Basta dizer que os livros psicografados por médiuns constituem os verdadeiros bestsellers brasileiros, ignorados pela mídia oficial, com tiragens muito superiores a qualquer livro de autor ainda vivo. Temos também outras formas de manifestação artística como a pintura e o desenho dos supostos espíritos de pintores já falecidos, geralmente os mais conhecidos do público. Os médiuns realizam estas pinturas em transe, algumas vezes com as duas mãos, constituindo um efeito maravilhoso tido como uma prova de fé pelos crentes. Há também os médiuns compositores de letras e músicas (destaco aqui as curimbas, músicas cantadas nos rituais das seitas afro-brasileiras que integram o rico folclore brasileiro e também o cancioneiro popular). Estes “dons” se desenvolvem à medida que o transe vai sendo controlado e os indivíduos melhoram, tornando-se mais assertivos, mais equilibrados e, sobretudo, muito criativos. É essa a liberação de energias criativas que Mongruel (1947) considerou como sendo o elemento terapêutico deste cultos, conforme escreveu:

Chamo a atenção dos cientistas para (...) as "escolas de formação de médiuns” nas quais a experiência coletiva empírica constituiu real fase précientífica de uma psicologia dos distúrbios da emotividade. A terapêutica consiste em educar o paciente para o uso normal da psicautonomia, e que equivale a 


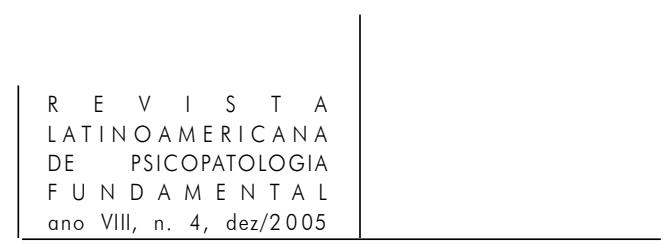

provocar estados semelhantes aos períodos de inspiração dos artistas ou de imaginação criadora dos sábios e inventores.

Janet (1925) já observara que o despertar de energias criativas em tais indivíduos era o que geralmente promovia a cura, que se manifestava como um ganho adicional em suas personalidades.

Muitas formas de transtornos psíquicos e o imenso contingente dos padecentes nervosos cada vez mais numerosos em nosso país, em especial aqueles com alta capacidade de transe do paciente, poderiam se beneficiar desta transeterapia devidamente adaptada ao tratamento psicoterápico. A conceituação deste problema como uma patologia mental e sua desconexão da cultura e do folclore, reprimindo-se ainda mais as energias criativas que permitem ao homem adaptar-se às variadas condições de seu meio, poderiam ser revistas e canalizadas para um contexto cultural e social benéficos.

\section{Referências}

Azam, E. Hypnotisme, doublé conscience et altérations de la personnalité. Paris: J. B. Baillière et Fils, 1887.

CÂmara, F. P. Hipnose e psiquiatria. Insight - Psicoterapia, n. 6, p. 17-20, 1996.

Hipnose, hipnotizabilidade e psicoterapia. Jornal Paulistano de Psicossomática, n. 3, p. 58-9, 1997.

Neurofisiologia da hipnose e estados correlatos. Insight - Psicoterapia, n. 7, p. 16-9, 1997.

Fenômenos hipnóticos e transtornos dissociativos. Insight - Psicoterapia, n. 8, p. 17-20, 1998.

Hipnose, hipnotizabilidade e psicoterapia. Jornal da Sociedade Médica de Petrópolis, n. 74, p. 8, jan.-fev./2001.

Cascudo, L. C. Dicionário do folclore brasileiro. São Paulo: Melhoramentos, 1980.

Chakraborty, A. Culture, colonialism and psychiatry. The Lancet, n. 337, p. 12047, 1991.

Janet, P. Principles of Psychoterapy. Londres: Macmillan Press, 1925.

LÉVI-Strauss, C. (1949). A eficácia simbólica. In: Antropologia estrutural. Rio de Janeiro: Tempo Brasileiro, s./d. p. 215-36.

Loyola, M. A. Médicos e curandeiros: conflito social e saúde. São Paulo: Difel, 1984.

Mars, L. P. La crise de possession. Port-au-Prince, Haiti: Imprimerie de L’Etat, 1955. 


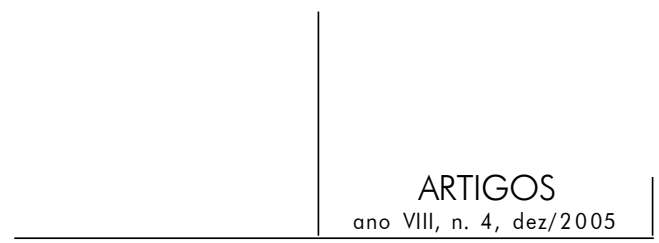

Mongruel, J. O transe de personificação verbal e a hipótese da psicautonomia. Anais do I Congresso Interamericano de Medicina [Rio de Janeiro, 1946], Sessão de Temas Livres, 1947, v. 2.

Oliveira, P. A. R. Coexistência das religiões no Brasil. Sincretismo Religioso, Revista Cultura, Petrópolis, Vozes, n. 71, p. 35-42, 1977.

Procópio, C. Kardecismo e umbanda. Rio de Janeiro: Pioneira, 1961.

SAshidHaRAn, S. P. Ideology and politics in transcultural psychiatry. In: Cox, J. L. (org.). Transcultural Psychiatry. Dover: Croom Helm Ltd., 1986, p. 158-78.

Spiegel, D.; Detrick, D.; Frischholz, E. Hypnotizability and Psychopathology. Am. J. Psychiatry, n. 139, p. 431-7, 1982.

Spiegel, H. An Eye-roll Test for Hypnotizability. Am. J. Clin. Hypnosis, n. 15, p. 25-8, 1972.

The grade 5 syndrome: the highly hypnotizable person. Int. J.Clin. Exp. Hypnosis, n. 22, p. 309-19, 1974.

\section{Resumos}

En este trabajo el autor considera las prácticas de cura basadas en los cultos animistas, bastantes difundidos en gran parte del Brasil. Estos cultos tienen como principio la conversión de sus líderes espirituales después de ser curados por supuesta intervención de espíritus tutelares del culto. Los líderes mencionados son ellos mismos ejemplos de la energía de los espíritus y también mediadores de los miembros de la comunidad con los espíritus. El autor considera que estos cultos de cura y conversión tienen como base el fenómeno del trance y posesión espiritual que, siendo controlada, tiene propiedades desensibilizadoras, puede restaurar el autocontrol del individuo, liberando sus fuerzas creativas. También amplía más el concepto considerando tal práctica como base de una terapia del trance insertada en la cultura popular.

Palabras claves: Trance y posesión, cultura popular, psicoterapia

L'auteur prend en compte dans ce travail les pratiques de cure dans le cadre de cultes animistes très répandus dans certaines communautés du Brésil. Ces cultes ont pour principe d'obtenir la conversion des chefs spirituels de ces communautés, après leurs guérisons attribuées aux interventions d'esprits tutélaires. Les chefs sont eux mêmes des exemples du pouvoir des esprits sur sa communauté et des médiateurs entre les individus et ces esprits. L'auteur considère que les cérémonies de cure et de conversion ont pour ressort essentiel le phénomène de transe et de possession, dont le contrôle produit des effets de désensibilisation, rend possible la reprise du self control 


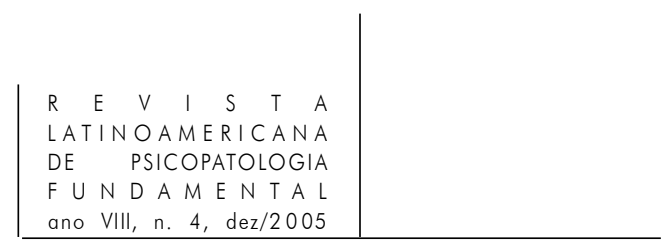

et libère les forces créatrices de l'individu. Ainsi, de telles pratiques constitueraient la base d'une thérapie par la transe insérée dans la culture populaire.

Mots clés: Transe et possession, culture populaire, psychothérapie

In this work the author considers the practice of cure based upon animist cults that are largely disseminated throughout Brazil. These cults have as principles the conversion of their spiritual leaders after being cured by the supposed interventions of protective supernatural beings. The leaders mentioned are themselves examples of the power of the spirits in their communities and are also mediators between the community members and the spirits. The author considers the phenomenon of trance and spiritual possession as the base of the cults of cure, which, if kept under control, has desensitization proprieties, can restore one's self control, freeing creative forces from within the individual. The concept is further enlarged to embrace such practices as the base of a trance therapy inserted in popular culture.

Key words: Trance and possession, folklore, psychotherapy 